Lexis Vol. XLI (1) 2017: 181-202

\title{
El duelo y el tiempo mítico en Rosa Cuchillo y La hora azul
}

\author{
Tania Torres Oyarce \\ University of Illinois at Chicago
}

\section{RESUMEN}

En este artículo, sostenemos que las novelas Rosa Cuchillo y La hora azul proyectan procesos individuales de duelo en un orden social mítico que se limita a reproducir el fantasma de la nación cercada (Ubilluz) como (seudo) propuesta de solución al conflicto armado acontecido en el Perú entre 1980-2000. En Rosa Cuchillo, la protagonista Rosa Cuchillo atraviesa un proceso de duelo por haber perdido a su hijo subversivo, Liborio, mientras que, en La hora azul, el protagonista Adrián Ormache sufre un proceso de duelo a causa de una crisis de la figura paterna idealizada que tenía de su fallecido padre militar. Estas experiencias individuales de duelo tienen como desenlace la apertura al orden social a través del mito del eterno retorno (Debord), en Rosa Cuchillo, y del mito del progreso (Benjamin) en La hora azul. Situados en el tiempo mítico, se hacen tangibles los alcances sociales de las novelas entendidos como una reproducción de propuestas que no cuestionan el fantasma de la nación cercada: Rosa Cuchillo propone un pachacuti de runas, mientras que La hora azul propone una ética tutelar que mantiene el status quo.

Palabras clave: duelo, mito, nación cercada, violencia política, Perú 


\section{ABSTRACT}

In this paper, I propose that the novels Rosa Cucbillo and La bora azul project individual processes of mourning in a mythical social order that limits itself to reproduce the phantom of the enclosed nation (Ubilluz) as a (seudo) proposal to solve the internal conflict that took place in Peru between 1980-2000. In Rosa Cuchillo the main character, Rosa Cuchillo, goes through a process of mourning due to the loss of his terrorist son, Liborio, whereas in La hora azul the main character, Adrián Ormache, undergoes a process of mourning due to the crisis of the idealized paternal figure he had of his dead military father. These individual experiences of mourning result in an opening to the social order by means of the myth of the eternal return (Debord) in Rosa Cuchillo and the myth of progress (Benjamin) in La hora azul. Located in a mythical time, the social consequences of the novels become apparent: they reproduce proposals that do not question the phantom of the enclosed nation, since Rosa Cuchillo proposes a pachacuti of runas, whereas La hora azul suggests a form of tutelary ethics that maintains the status quo.

Keywords: mourning, myth, enclosed nation, political violence, Peru

En este artículo, sostenemos que las novelas Rosa Cucbillo y La hora azul proyectan procesos individuales de duelo en un orden social mítico que se limita a reproducir el fantasma de la nación cercada (discutido por Juan Carlos Ubilluz) como (seudo) propuesta de solución al conflicto armado acontecido en el Perú entre 1980-2000. Con el fin de sustentar esta hipótesis, examinamos el duelo (en sentido freudiano) presente en cada novela. En el caso de Rosa Cuchillo, la protagonista Rosa Cuchillo atraviesa un proceso de duelo por haber perdido a su hijo, Liborio, quien pertenece al grupo subversivo Sendero Luminoso, mientras que, en el caso de La hora azul, el protagonista Adrián Ormache sufre un proceso de duelo a causa de una crisis de la figura paterna idealizada que tenía de su fallecido padre militar. Estas experiencias individuales de duelo tienen como desenlace la apertura al orden social a través del mito del eterno retorno (según Guy Debord), en el caso de Rosa 
Cuchillo, y del mito del progreso (según Walter Benjamin) en el caso de La hora azul. Una vez situados en el tiempo mítico, se hacen tangibles los alcances sociales de las novelas entendidos como la reproducción de propuestas que no cuestionan el fantasma de la nación cercada: Rosa Cuchillo propone, como respuesta a la violencia, un pachacuti de runas, mientras que La hora azul propone, ante esta realidad, una ética tutelar que mantiene el status quo.

Para desarrollar estos temas, dividimos nuestra discusión en dos secciones. En la primera, analizamos el proceso de duelo en cada novela a través del examen de las búsquedas individuales de Rosa Cuchillo y Adrián Ormache. En la segunda, nos acercamos a la relación entre el duelo y el mito del eterno retorno en el caso de Rosa Cucbillo, y a la relación entre el duelo y el mito del progreso, en el caso de la La hora azul, con el fin de examinar los alcances sociales de ambas novelas entendidos como la reproducción del fantasma de la nación cercada.

\section{El proceso de duelo: la búsqueda del familiar perdido}

En esta sección, sostenemos que Rosa Cuchillo y Adrián Ormache atraviesan experiencias individuales de duelo en sus procesos de búsqueda de un familiar perdido. Para tratar esta cuestión, hacemos un deslinde entre las nociones de duelo y melancolía a partir del artículo "Duelo y melancolía” de Sigmund Freud y, sobre esta base, analizamos las búsquedas de ambos personajes.

Como señala Freud, el duelo y la melancolía son nociones relacionadas que implican, en términos generales, la reacción de un sujeto ante una pérdida. En relación con la caracterización del duelo, aunque de manera extensible a la melancolía, el autor señala lo siguiente: "El duelo es, por regla general, la reacción frente a la pérdida de una persona amada o de una abstracción que haga sus veces, como la patria, la libertad, un ideal, etc”. (1986: 241). Se trata de experiencias dolorosas para un sujeto, las cuales le quitan las fuerzas al yo por enfrentarse, este último, a una pérdida, como continúa Freud: "El duelo normal vence sin duda la pérdida del objeto 
y mientras persiste absorbe de igual modo todas las energías del yo" (1986: 252). Es decir, toda la libido del yo está orientada a enfrentarse con la pérdida con el fin de superarla. La melancolía, por su parte, aunque constituye también la reacción frente a una pérdida, se "nos muestra todavía [como] algo que falta en el duelo: una extraordinaria rebaja en su sentimiento yoico, un enorme empobrecimiento del yo" (1986: 243). Esto quiere decir que el yo se ha hecho pobre y vacío, se humilla ante los demás, se llena de reproches contra sí mismo y se considera insignificante. ${ }^{1}$

Lo interesante, a partir de la base común al duelo y la melancolía, es que la distinción entre ambas nociones radica en el modo en que el sujeto concibe la pérdida. Así, en relación con el duelo, “El examen de realidad ha mostrado que el objeto amado ya no existe más, y de él emana ahora la exhortación de quitar toda libido de sus enlaces con ese objeto" (1986: 242). Sin embargo, en relación con la melancolía, ocurre algo distinto: hay "una identificación del yo con el objeto resignado" (1986: 246). Es decir, el yo pasa a ser concebido como una instancia de aquello que se perdió. De este modo, como señala Freud, para el individuo, "En el duelo, el mundo se ha hecho pobre y vacío; en la melancolía, eso le ocurre al yo mismo" (1986: 243). Así, el duelo implica una relación entre el yo y el mundo, ${ }^{2}$ mientras que la melancolía constituye un ensimismamiento y un empobrecimiento del yo.

Sobre esta base conceptual, nos acercamos a los procesos de búsqueda individual de los personajes Rosa Cuchillo y Adrián Ormache. Dos son las preguntas que orientan nuestro análisis: ¿cuál es la reacción ante la pérdida? y ¿ existe una aceptación de que lo que se perdió es ajeno al yo, o existe una identificación entre el objeto perdido y el yo? Por medio de la primera pregunta, nos

\footnotetext{
1 En último término, la melancolía está ligada al sentimiento de culpa; sin embargo, nos limitamos a los aspectos estrictamente relevantes para nuestra discusión. Ver la nota al pie 9.

2 La relación entre el sujeto y el mundo será relevante en la siguiente sección, puesto que, como discutiremos, el desenlace del duelo constituye la apertura a la dimensión social mítica de las novelas.
} 
situamos en el ámbito común al duelo y la melancolía, mientras que, por medio de la segunda, podemos determinar si, en los casos examinados, se trata de experiencias de duelo o de melancolía. Para responder estas preguntas, nos situamos en dos momentos clave en los que se nos brindan pistas al respecto, a saber, al inicio y al final de las búsquedas de los protagonistas.

Con respecto a Rosa Cuchillo, la reacción inicial ante la pérdida (la muerte de Liborio), situada al inicio de la novela, radica en que ella misma muere de pena a causa del dolor que le provoca lo sucedido. Lo fundamental de esta reacción es que Rosa no se queda inmóvil, sino que, al encontrarse en el mundo de los muertos, el dolor la mueve a emprender el camino de la búsqueda de su hijo. De hecho, al inicio del camino, se ve a Rosa despidiéndose de su pueblo: "Pobre mi pueblo, dije, pobre mi tierra. Ahí te dejo (¿para siempre?). Y miré los molles de las lomas, las piedras de alaymosca rodando por la quebrada, los altos eucaliptos que rodeaban las huertas, los tunales con sus espinas erizadas y los magueyes estirándose sobre las cabuyas" (Colchado Lucio 2009: 10). Así, la despedida del lugar natal indica el inicio del viaje de la protagonista.

No obstante, la despedida del pueblo no es ajena al dolor: "Y me despedí poniendo mi mano en mi corazón, besando, amorosa, la tierra. ¡Adiós alegrías y penas, consuelos y pesares, adiós! Suspiré hondo antes de alejarme, recordando mi mocedad" (Colchado Lucio 2009: 10). El inicio del camino de Rosa está cargado de referencias a la aprehensión de la protagonista por su pueblo. Sin embargo, esta suerte de añoranza con respecto al pasado, en la que recuerda su "mocedad", no es un obstáculo que le impida emprender el camino. Es decir, la reacción ante la pérdida de Liborio constituye un dolor que la llena de agencia, porque la moviliza, en una suerte de deber hacer ético, a salir de sí misma a vivir en el mundo de los muertos. La fuerza de su movilización es sorprendente: esta empresa consume todas las energías de la protagonista, quien no se desanima, a pesar de que no tiene ni una sola referencia clara ni direcciones precisas para orientarse en el mundo en el que se sumerge, puesto que lo único que se le hace saber al llegar es que en él se encuentra su hijo Liborio. 
Los episodios antes mencionados nos brindan pistas no solo en relación con la reacción cargada de dolor ante la pérdida como ámbito común al duelo y a la melancolía, sino que también proporcionan elementos de análisis en relación con la experiencia de Rosa como un proceso de duelo y no de melancolía. Así, a pesar de que la muerte de Rosa podría parecer melancolía a primera vista, porque el empobrecimiento del yo sería tan extremo que la conduciría a la muerte, Rosa no se queda ensimismada, como si el empobrecimiento fuera del yo, sino que sale de sí misma a enfrentar el mundo (empobrecido a causa de un objeto perdido) con una agencia movilizada por el dolor, lo cual es propio del duelo. Es más, la muerte de Rosa se transforma en la posibilidad efectiva de emprender la búsqueda de Liborio: su hijo se encuentra en el mundo de los muertos, por lo que su peregrinaje debe ocurrir en dicho entorno. Por consiguiente, nos situaríamos en el ámbito del duelo y no de la melancolía: el camino que emprende la protagonista está marcado siempre por la búsqueda de un otro que ya no se encuentra en el mundo, mas no por un ensimismamiento o un empobrecimiento del yo.

El segundo momento en el que nos centramos es en la satisfacción de la búsqueda de su hijo, a saber, cuando tiene lugar el encuentro entre la protagonista y Liborio al final de la novela. ${ }^{3}$ El encuentro entre ambos tiene lugar cuando Rosa ingresa en el Janaq Pacha junto con su perro guía Wayra: "Lejos, a la distancia, reconocí a mi Liborio. Avanza solo, envuelto en su poncho, calzando llanquecitos. No venía alegre, tenía un aire de preocupación. Corriendo me fui a abrazarlo" (Colchado Lucio 2009: 260). Liborio, por su parte, la reconoce inmediatamente, porque el Gran Gápaj (el creador o hacedor del universo) le avisó previamente que ella llegaría. El encuentro lleva consigo el cierre de la búsqueda de la protagonista. $\mathrm{Al}$ respecto, Rosa recoge, sin ningún tipo de dolor, estas palabras de

\footnotetext{
3 Nos limitamos a los aspectos que son relevantes en relación con la caracterización de la experiencia de Rosa como sujeto individual. Hay aspectos en relación con el mito del eterno retorno que tratamos en la siguiente sección, dado que esta consideración nos sitúa de lleno en el ámbito de los alcances sociales de la obra, objeto central del siguiente apartado.
} 
Liborio cuando él se disponía a partir: "Estoy volviendo a la tierra, respondió, me envía el Padre a ordenar el mundo. ¿Un pachacuti?, dije. Sí, es necesario voltear el mundo al revés. No dijo más, me abrazó, me dio un beso en la mejilla y partió" (Colchado Lucio 2009: 261). En este sentido, la motivación del sujeto para emprender el camino, caracterizada como una reacción ante la pérdida de su hijo y por un empobrecimiento del mundo (y no del yo) por la falta del otro, finaliza en un momento determinado (el encuentro con Liborio), con lo cual, Rosa acepta que su hijo había muerto. Por lo tanto, afirmamos que Rosa Cuchillo atraviesa una experiencia de duelo y no de melancolía.

Nótese que los dos momentos del duelo de Rosa Cuchillo, que hemos examinado, constituyen el principio y el final del hilo conductor del texto, es decir, el marco en el que se desarrolla la novela. Así, la búsqueda individual de Rosa por su hijo ocupa el primer plano de la historia. Al respecto, es relevante referir también, a manera de ejemplo, uno de los comentarios, situado en numerosos pasajes a lo largo de la novela, que hace Rosa acerca de su hijo y su pertenencia a Sendero Luminoso mediante la inserción de su voz en segunda persona: “¿Acaso no fue Pedro Orcco, el dios montaña, quien te [Liborio] ayudó a escapar durante el ataque de la cárcel de Ayacucho?” (Colchado Lucio 2009: 169-170). De este modo, aun cuando se haga una alusión al contexto de violencia en el que está involucrado Liborio, lo que prima, nuevamente, es la experiencia de Rosa como sujeto que busca un objeto perdido: la lectura de los hechos se realiza desde su perspectiva. En este sentido, si bien se narra lo horrible de la violencia del conflicto armado, el énfasis no se encuentra, en sentido estricto, en ello, sino en un personaje que se ve involucrado en dicho conflicto solo debido a que el objeto de su búsqueda, Liborio, forma parte de él; es más, como discutiremos en la siguiente sección, quien llevará a cabo una reflexión ideológica sobre el país y se comprometerá a intervenir directamente para buscar un cambio en el Perú no es Rosa, eje central del relato, sino, fundamentalmente, Liborio. Así, la consideración del lector sobre el escenario de la violencia política se encuentra mediada por la experiencia de duelo de Rosa. 
Con respecto a Adrián Ormache, la pérdida de la que trata $L a$ hora azul es la de una figura paterna idealizada. Hasta antes del inicio de la búsqueda por el pasado de su padre, se podría sintetizar la concepción que tenía Adrián de este hombre por medio de dos cuestiones. Por un lado, está la visión de la figura paterna que la madre le había transmitido: "convenía mantener en alto el apellido paterno. Como no podíamos eliminarlo, era mejor darle cierto lustre con nuestra propia conducta, convenientemente subrayada por una deliberada ingenuidad" (Cueto 2007: 25). Así, independientemente de la tesitura del padre real, había que ensalzar su apellido. Por otro lado, Adrián había alimentado su propio recuerdo con la ingenuidad e idealismo que le habían sido transmitidos por su madre con respecto a su padre mediante, en primer lugar, el hecho de poner a un lado los pocos recuerdos que tenía de él: "Yo había hecho todo lo posible por apartarme de esos pocos recuerdos suyos" (Cueto 2007: 22) y, en segundo lugar, la construcción de una imagen idealizada de él: "yo tenía algunas ideas propias sobre mi padre. A veces, me gustaba ceder a mis fantasías y pensar que había sido un gran militar, un héroe de la guerra con Sendero" (Cueto 2007: 26). De este modo, Adrián tiene la imagen de un héroe idealizado con respecto a su figura paterna.

Tras la muerte de la madre, empieza el desenmascaramiento o la pérdida de esta imagen idealizada de la figura paterna. Su reacción ante ella se comprende en particular con respecto a dos momentos. En el primero de ellos, no hay propiamente una reacción ante la pérdida, sino solo la toma de conciencia de la existencia de Miriam, chica a la que su padre violó y de la cual se enamoró durante el conflicto armado. La figura de la muchacha es introducida a través del encuentro de Adrián con su padre, cuando este último está viejo y enfermo en el Hospital Militar. El padre le dice lo siguiente: “oye, quiero que sepas algo, hay una chica, una mujer que conocí una vez, o sea, no sé si puedes encontrarla, allá, búscala si puedes, cuando estaba en la guerra. En Huanta. Una chica de allí. Te lo estoy pidiendo por favor. Antes de morirme" (Cueto 2007: 23). Así, al igual que Rosa, la información que recibe el protagonista es muy 
escueta: no hay referencias específicas, sino solo algunas vaguedades recogidas en los recuerdos que el padre le comunica acerca de Miriam, la chica provinciana que lo cautivó.

En el momento de la novela referido, Adrián no sabe que este pedido cambiará su tranquila vida familiar. Para que ello ocurra, hará falta que tenga lugar el segundo momento: la llegada del extranjero de Rubén, su hermano, con motivo de la muerte de su madre. En el almuerzo que ambos comparten antes de que Rubén emprenda el viaje de regreso, este último le confirma a Adrián la información que le había transmitido su padre con respecto a Miriam:

-Pero ¿sabes una cosa? -agregó sonriendo, poniendo los dos brazos delante-. Hubo una que se le escapó, oye. Una que se le escapó una vez.

-¿Una que se le escapó?

-Así me dijeron, algo así. Bueno, pues, como quien dice, al mejor cazador se le va la paloma. El viejo no era infalible tampoco. Una prisionera se le escapó porque él se había enamorado de ella, fíjate (Cueto 2007: 38).

Esta confirmación de los datos que sabía, también le brinda información nueva: Rubén le dice a Adrián que su padre "se había enamorado" de aquella mujer. Desde este momento, tiene lugar un vuelco en la vida de Adrián, porque lo que le dijo su hermano se convertirá en su nuevo leitmotiv.

En este punto, encontramos una respuesta a la pregunta con respecto a la reacción ante la pérdida: al igual que en el caso de Rosa, hay en Adrián una fuerza que lo moviliza a la acción, es decir, en algún sentido, Adrián cae en la cuenta de que hay algo que ha perdido (a causa de la crisis de la figura paterna idealizada) que lo mueve a rastrear el verdadero pasado de su padre. $\mathrm{Al}$ respecto, citamos un extracto de la conversación que tiene con Platón, el amigo con quien comparte sus confidencias, cuando Adrián ha iniciado ya su búsqueda que, en lo posterior, consumirá todas las energías del yo: “- $\mathrm{i}$ qué crees que te va a decir esa chica? / -Bueno... quiero que ella me diga si mi papá fue tan desgraciado como dicen” (Cueto 2007: 149). 
En este diálogo, se hace palpable lo que mencionamos anteriormente: la pérdida de la figura idealizada del padre y el deseo de conocer el pasado de este hombre hacen que Adrián empiece la búsqueda de Miriam, que es aquella quien, como cree el protagonista, le puede ofrecer información acerca de su pasado militar.

Con el fin de determinar si la experiencia de Adrián es de duelo o de melancolía, nos situamos en el desenlace de la historia. Una vez acabados los amoríos con Miriam (luego de su muerte, incluso), ya cuando Adrián está rehaciendo su vida, de vuelta, junto a su familia, el protagonista empieza a mirar hacia atrás, al pasado compartido con Miriam, y, al considerar la división entre ricos y pobres, que, en último término, distingue a la gente como él mismo y a la gente como Miriam, Adrián se distancia de la búsqueda emprendida y ya finalizada. Al respecto, menciona lo siguiente: "Es obvio que yo no voy a hacer nada para remediar esa injusticia tan enhebrada a la realidad, no puedo hacer nada, no voy a ayudarlos, a lo mejor tampoco me interesa" (Cueto 2007: 274). Como se puede notar, no existe una identificación entre la pérdida y la búsqueda del pasado del padre, y el yo de Adrián. Al contrario, el pasado del padre, del cual Miriam forma parte, se sitúa fuera del protagonista. Se enfatiza esta cuestión más adelante: "Necesito adormecerme otra vez al gran sueño de lo que creo ser, apurarme en regresar a mi sitio, correr las sábanas blancas y limpias del olvido sobre mi cabeza y entregarme al ruido menudo, olvidarme de todo eso que va a morir con Miriam" (Cueto 2007: 274). ${ }^{4}$ Así, Adrián decide "regresar a su sitio", es decir, en lugar de identificar el pasado con su propio yo, decide continuar con su vida dejando atrás dicha búsqueda de la figura paterna idealizada. En este sentido, como tratamos con respecto a Rosa Cuchillo, no hay un empobrecimiento del yo, lo cual lo situaría en el ámbito de la melancolía, sino que se trata de una experiencia de duelo.

\footnotetext{
4 En la siguiente sección, tratamos la relación de Adrián Ormache con el mito del progreso, a partir de lo cual, según nos parece, adquiere sentido esta cita en relación con los alcances sociales de la novela.
} 
Nótese que, al igual que con Rosa, el énfasis está en el carácter individual (y autobiográfico) de la experiencia de Adrián. Si bien es cierto que se rastrea el pasado del padre militar y se atisba la presencia de, en palabras de Víctor Vich, "una verdad obscena, atroz" de que su padre había sido "un militar violador de mujeres campesinas" (Paredes 2009: 112), el énfasis no se encuentra en el tratamiento de los crímenes de los militares (ni siquiera en los crímenes de su padre). Por el contrario, el escenario del conflicto armado funciona como telón de fondo. Es más, la relación entre su padre y Miriam se desdibuja ante el proceso que atraviesa el protagonista: en último término, lo que prima es la apropiación del pasado en el presente posterrorista de un abogado limeño y cómo articula este dicha experiencia con su vida cotidiana.

En síntesis, tanto en Rosa Cuchillo como en Adrián Ormache hay una reacción ante una pérdida, la cual se transforma en una fuerza que los moviliza a emprender un camino de búsqueda que consume todas las energías del yo. Sin embargo, esta búsqueda no constituye una identificación entre el objeto perdido y el yo, sino que se sitúa fuera de ellos, motivo por el cual sostenemos que, en ambos casos, se trata de experiencias de duelo que se resuelven con el desenlace de sus respectivas búsquedas.

Es relevante hacer notar que el deslinde entre duelo y melancolía permite enfatizar que las novelas abren la posibilidad de apertura al escenario social. En caso de que los protagonistas fueran personajes melancólicos, sus experiencias serían completamente intimistas, por lo que plantearse la pregunta de la relevancia social de las experiencias individuales de los protagonistas no tendría cabida. A pesar de ello, vale la pena reiterar que los personajes utilizan todas las fuerzas yoicas en búsquedas estrictamente individuales, por lo que las experiencias de duelo opacan, en gran medida, en ambas novelas, el irresuelto escenario social de convulsión en el Perú. Sin embargo, el mismo hecho de que el duelo esté presente hace que la pregunta por la apertura al mundo exterior no sea vana. En sentido más amplio, cabe preguntarse cuál es la dimensión social del duelo de los personajes, cuestión a la que nos acercamos en la siguiente sección. 


\section{El tiempo mítico y los alcances sociales del duelo}

En este apartado, sostenemos que el duelo de Rosa Cuchillo y de Adrián Ormache se entrelaza con una dimensión mítica: el mito del eterno retorno en el caso de Rosa Cuchillo y el mito del progreso en el caso de La hora azul. El enlace entre las temporalidades del duelo y de estos mitos permite acercarse a los alcances sociales de ambas novelas, entendidos como una reproducción del fantasma de la nación cercada: Rosa Cuchillo propone un pachacuti de runas, mientras que La bora azul propone una ética tutelar que mantiene el status quo.

Antes de sustentar nuestra propuesta, tratamos la noción de mito según Guy Debord, y caracterizamos brevemente el mito del eterno retorno según el mismo autor y el mito del progreso según Walter Benjamin. Debord caracteriza el mito de la siguiente manera: "El mito es la construcción unitaria del pensamiento que garantiza y organiza todo el orden cósmico en torno del orden que esta sociedad ha en efecto ya realizado en sus fronteras" (1995: 80). Así, el mito es una suerte de principio ordenador del entorno social, el cual establece sus posibilidades y sus límites.

Dentro de esta presentación amplia de lo que constituye el mito, es posible situar los dos tipos de mitos que nos interesan: el mito del eterno retorno y el mito del progreso. En relación con el primero, el mismo Debord señala lo siguiente:

El tiempo cíclico domina ya en la experiencia de los pueblos nómades, porque las mismas condiciones se encuentran nuevamente ante ellos a cada momento de su pasar: Hegel señala que "el vagabundeo de los nómades es solamente formal, pues está limitado a espacios uniformes". La sociedad que, fijándose localmente, da al espacio un contenido a través del agenciamiento de lugares individuales, se encuentra por ello mismo encerrada al interior de esta localización. El retorno temporal en lugares similares es ahora el puro retorno del tiempo en un mismo lugar, la repetición de una serie de gestos (1995: 80). 
De este modo, la repetición (temporal) ocupa un lugar fundamental en el mito del eterno retorno, debido a que, al repetirse las circunstancias, se repiten también las respuestas a ellas.

En relación con el segundo, el mito del progreso, de manera opuesta a lo que se plantea con respecto al mito del eterno retorno, la historia se concibe de manera lineal: no se repite el pasado, sino que la orientación fundamental radica en la construcción del futuro. Esta construcción del futuro se entiende en relación con el avance técnico. Al respecto, es relevante citar la tesis 11 de Walter Benjamin en "Sobre el concepto de la historia": "El desarrollo técnico era para ella [la masa obrera] el declive de la corriente con la que creía estar nadando. De allí no había más que un paso a la ilusión de que el trabajo en las fábricas, que sería propio de la marcha del progreso técnico, constituye de por sí una acción política” (2013). El mito del progreso constituye el mito de la Modernidad, como se señala en esta tesis: cualquier avance técnico (y, en sentido amplio, cualquier mejora) se entiende a priori como una forma de progresar. $\mathrm{Al}$ respecto, Stella Wittenberg señala lo siguiente:

Benjamin lanzó fundamentalmente sus críticas y diatribas contra el mito del progreso histórico automático y en su obra "Über den Begriff der Geschichte" [Sobre el concepto de la historia] desarrolla su planteamiento, en el que observa la identificación que se ha hecho del progreso tecnológico con el progreso histórico, error que precipitó a la clase obrera alemana hacia objetivos políticos equivocados (2005: 195).

Así, el mito del progreso, entendido de manera general, consiste en creer (equivocadamente, según Benjamin) que, en el transcurso de la historia, cualquier mejora presente constituye indefectiblemente un cambio en pos de la construcción de un futuro mejor.

En definitiva, el mito, entendido como principio articulador de la sociedad, desde la perspectiva que adoptamos, se presenta de dos maneras opuestas. Por un lado, está el mito del eterno retorno, en el cual la noción de repetición es crucial: los seres humanos reaccionan de la misma manera que como se hizo en el pasado al encontrarse 
en situaciones semejantes. Por otro lado, está el mito del progreso, en el que, de manera contraria a lo mencionado en relación con el mito anterior, se concibe la historia de modo lineal y se identifica el avance (técnico) con el progreso.

Sobre esta base, nos acercamos, en primer lugar, al caso de Rosa Cuchillo. Como mencionamos en la sección anterior, cuando la protagonista ingresa junto a Wayra en el Janaq Pacha, se cierra su proceso de duelo. Al finalizarse este proceso, se hace relevante la consideración del mito del eterno retorno, debido a que, al estar en el Janaq Pacha, Rosa siente "una transformación en mi [su] cuerpo" (Colchado Lucio 2009: 231). Ante su sorpresa, Wayra le dice lo siguiente: "No te alarmes, me dijo, estás volviendo a ser lo que en verdad eres: alguien que siempre habitó estos lugares y que sin embargo lo olvidó" (Colchado Lucio 2009: 232). De este modo, se hace patente el mito del eterno retorno: a medida que Rosa avanza y se fija en el lugar en el que se encuentra, empieza a reconocer el entorno. Este proceso culmina con el descubrimiento de su verdadera identidad, el cual es confirmado por su guía, Wayra: “-Reconócete, ¿no eres acaso Cavillaca, la bellísima diosa que un tiempo vivió en la tierra en la época de los incas?" (Colchado Lucio 2009: 232). Así, tiene lugar un proceso de repetición: al encontrarse en el Janaq Pacha, la antigua Rosa Cuchillo se reconoce a sí misma como Cavillaca. ${ }^{5}$

Sin embargo, al limitarnos a Rosa, desde la perspectiva mítica, estamos todavía en una perspectiva individual, en la que el duelo se entrelaza con el mito del eterno retorno: este último precede y sucede al duelo, el cual constituye un tránsito entre dos momentos de la protagonista. El mito del eterno retorno adquiere un matiz social solamente cuando ocurre el encuentro con Liborio, momento en el que, en sentido estricto, se satisface la búsqueda de la protagonista. Para ilustrar esta cuestión, retomamos las palabras de

5 Cavillaca es una huaca-doncella que aparece en el Manuscrito de Huarochirí y que hace uso de su belleza como mecanismo de poder, porque, a través de ella, controla a los huacas que desean acostarse con ella (Maceda 2010: 56). 
Rosa, que recogen las de Liborio cuando este último se disponía a salir: "Estoy volviendo a la tierra, respondió, me envía el Padre a ordenar el mundo. ¿Un pachacuti?, dije. Sí, es necesario voltear el mundo al revés" (Colchado Lucio 2009: 261). Así, como señala Víctor Quiroz, "el encuentro entre madre e hijo en el Janaq Pacha anuncia la posterior restauración del orden andino que es llevada a cabo por Liborio quien desciende a la tierra para realizar el pachacuti" (2006: 101). El pachacuti es, quizás, la manifestación andina más importante del mito que consideramos: es necesario dar inicio a un nuevo tiempo. Por lo tanto, a la experiencia individual de Rosa le sucede la apertura social de dicha experiencia: el duelo y el mito del eterno retorno constituyen dos temporalidades que se suceden, puesto que, en la novela, solo una vez que el proceso de duelo ha finalizado, puede tener lugar la proyección a la dimensión social mítica, entendida como pachacuti.

No obstante, el inicio de un tiempo nuevo no constituye una construcción de un futuro nuevo, sino, más bien, de una restitución del pasado. Al respecto, es interesante revisar, en la misma línea de Juan Carlos Ubilluz (2009: 52-53), la idea de revolución mesiánica (pachacuti, desde esta perspectiva mítica) que se construye a lo largo de la novela en torno a Liborio, el camarada Túpac, "héroe [andino] de dimensiones mitológicas” (Galdo 2000: 95). Luego de estar un tiempo en las filas de Sendero Luminoso y formar parte de la lucha armada, cae en la cuenta de que los miembros del grupo guerrillero no son runas (o naturales), como él, sino que son mistis (o blancos), quienes, al estar en el poder, se olvidan de los runas, como la historia del Perú y el mismo presente de la novela lo demuestran. Dicha distinción parece retomar la utopía arcaica de Mario Vargas Llosa, la cual está marcada por un andinismo en el que "Los malvados son blancos [mistis], generalmente, y los buenos, indios [runas]” (2009: 327). Así, para Liborio, la verdadera revolución y, en último término, el pachacuti al que se orienta tras despedirse de Cavillaca, se articulan en torno a la toma del poder por parte de los naturales, lo cual implica situarse en el pasado, antes de la llegada de los españoles, es decir, se trata de un regreso a un tiempo idílico en 
el que, como señala Juan Carlos Galdo, “las masas de campesinos... supuestamente conservan indemne una cosmovisión que será restaurada luego del Pachacuti” (2000: 95), lo cual implica poder bailar las propias danzas sin vergüenza y poder hablar tranquilamente el runa simi (el quechua). ${ }^{6}$ De este modo, la proyección social de Rosa Cuchillo, que se manifiesta en el encuentro entre Rosa y su hijo, radica en la búsqueda de una suerte de utopía arcaica en el marco de un eterno retorno, estrictamente andino, en la que únicamente los naturales ocupan un lugar. En otras palabras, lo mencionado quiere decir que, en la novela, se propone que 'superar' el conflicto significa 'retornar' a un pasado-utópico.

En el caso de Adrián Ormache, a diferencia de Rosa Cucbillo, no hay que esperar a finalizar la novela para darse cuenta de que el proceso de duelo del protagonista se encuentra enmarcado por el mito, en particular, por el mito del progreso. Desde el inicio, Adrián hace una descripción autobiográfica a través de la cual se evidencia que su propia vida es un reflejo de este mito: es un abogado de clase alta cuyo salario alcanza los 9,000 dólares mensuales; tiene una familia tradicional: está casado con Claudia, una mujer guapa, con estilo y de buenos modales, y tiene dos hijas; vive en el distrito más exclusivo de Lima, San Isidro, rodeado de lujos; viaja al extranjero con cierta regularidad; y se frecuenta con políticos amigos. En general, su diario vivir consiste en el mito del progreso entendido en relación con la acumulación de bienes y/o riquezas a través de la prestación de sus servicios, lo cual le permite asegurar un futuro cómodo y tranquilo.

Lo que caracterizó su duelo, la crisis de la figura paterna idealizada y la búsqueda obsesiva del pasado de su padre a través de Miriam, en lugar de provocar un cambio en su vida y una vía de escape del mito del progreso, se convierte solamente en un parén-

\footnotetext{
6 En último término, esta propuesta implica la construcción de unos Andes concebidos desde un imaginario cargado de prejuicios (Vich 2010: 157). Por ejemplo, se presupone un pasado prehispánico (¿incaico?) libre de conflictos sociales, lo cual es falso; además, se propone la vuelta al quechua, lo cual ignora la diversidad lingüística de los Andes peruanos.
} 
tesis, con respecto a su vida normal, del cual su familia no forma parte. Así, cancela reuniones laborales y responde con evasivas ante los cuestionamientos de su esposa; además, su secretaria, su socio y Claudia notan que su conducta es distinta, pero Adrián responde negando que haya ocurrido algún tipo de cambio. Su comportamiento, en palabras de Claudia, se caracteriza por un "permanente estado de distracción” (Cueto 2007: 229). Por lo tanto, este paréntesis se caracteriza por el reordenamiento de sus prioridades: ${ }^{7}$ el mito del progreso, por el cual había trabajado durante toda su vida, pasa a estar subordinado al proceso de duelo. ${ }^{8}$

No obstante, este paréntesis que problematiza al protagonista, a la larga, no cambia nada, debido a que, una vez finalizado su romance con Miriam (a través del cual intenta saber más de su padre) y, en definitiva, tras su muerte, la vida de Adrián Ormache vuelve a la normalidad:

Después de todos los lujos, de los viajes de la imaginación y del deseo tenemos que regresar a lo que nos rodea. La realidad es la resignación. Tenemos que hacer el empinado camino de vuelta de nuestros viajes imaginarios (...). Y nuestra tragedia no es comprobar que hemos dejado de amar o de querer a esa persona [Claudia, su esposa], sino que detrás de las amarguras la seguimos queriendo sin comprenderlo, con la pasión resignada de la costumbre (Cueto 2007: 297).

De este modo, la novela se limita a proyectar en el orden social una experiencia del orden individual, a saber, la permanencia del orden hegemónico (es decir, del mito del progreso de acumulación de riquezas que Adrián ejemplifica), lo cual implicaría también aceptar la división (infranqueable) entre ricos y pobres, como señala Vich: "la novela termina por mostrarnos una sociedad donde

7 Como discutimos anteriormente, entendemos que las prioridades de Adrián Ormache son aquellas que caracterizan el mito del progreso de un limeño pudiente: tiene una familia y trabajo estables, se reúne con amigos regularmente, viaja al extranjero, etc.

8 Sin embargo, en sentido estricto, ello no supone la renuncia a dicho mito, debido a que el estilo de vida de Adrián no cambia. 
todos aceptan su desarticulación y donde ninguna acción colectiva puede emprenderse" (2009: 243). Ni siquiera la ayuda que Adrián le brinda a Miguel constituye un cambio, sino que, como continúa Vich, se limita a ser una suerte de "acto caritativo" (2009: 242), lo cual es un comportamiento propio de las clases altas con respecto a las clases bajas, como señala Vich: "No se está tratando de reformular lo existente, de reconstituir la sociedad a partir de una forma de organización que distribuya mejor, que articule más a la ciudadanía, a los diferentes sectores sociales, sino se sigue manteniendo una estructura tutelar de arriba a abajo a pesar de la violencia que vivimos" (Paredes 2009: 114). Esta visión se puede sintetizar en palabras del mismo Adrián: "Es obvio que yo no voy a hacer nada para remediar esa injusticia tan enhebrada a la realidad, no puedo hacer nada, no voy a ayudarlos [a los pobres y a las víctimas del conflicto armado], a lo mejor tampoco me interesa" (Cueto 2007: 274). De este modo, Adrián pasa a tener una conducta "aparentemente más 'humana”" (Paredes 2009: 114) de ética tutelar dentro del orden hegemónico: el rico hace obras de caridad a favor del pobre sin promover un cambio en la sociedad dividida. Así, desde nuestra perspectiva, lo que ocurre es que, una vez finalizado el duelo, se reordenan las prioridades de Adrián, con lo que el mito del progreso vuelve a ocupar el lugar primordial.

Por lo tanto, se puede afirmar que tanto en Rosa Cuchillo como en La hora azul no se propone ninguna alternativa al estado de cosas que prima en el país. En la primera, se invita a situarse en la esfera del ámbito andino a partir del mito del eterno retorno, el cual supone el advenimiento de un pachacuti del que están excluidos los mistis. En la segunda, en cambio, Adrián Ormache se sitúa en la otra orilla, a saber, aquella centrada en el mito de progreso limeño que, más allá de adoptar una ética tutelar, no hace nada para que cambie la sociedad desarticulada que caracteriza al Perú. De este modo,

9 Vich enmarca los fragmentos que citamos dentro de la consideración de la culpa de Adrián Ormache, tanto en la relación de este con Miriam como en la ayuda que le ofrece a Miguel. No nos detenemos en esta cuestión por no ser nuestro foco de atención. 
el haber atravesado una experiencia de duelo, en ambos casos, se presenta como un proceso conservador de alternativas que no permiten superar las divisiones presentes en el país.

Con respecto a este último punto, es pertinente hacer una referencia al fantasma de la nación cercada tratado por Ubilluz. José E. Cornelio lo sintetiza en los siguientes términos:

'el fantasma de la nación cercada', cuyo subtexto tiene su origen en el cuestionado Informe de Uchuraccay de 1983, (...) en líneas generales sostiene la diferenciación de un Perú oficial, moderno, democrático, urbano, y otro Perú tradicional, arcaico, rural, atrasado, anclado en una visión mágico-religiosa del mundo, donde se hallaría plenamente la cultura andina (2009: 4).

Las novelas examinadas se ajustan ampliamente a esta división entre dos ámbitos dentro del Perú: desde nuestra perspectiva, se trata de dos discursos míticos que caracterizan el fantasma, asociados cada uno a entornos distintos. En este sentido, aunque el Perú "tradicional” sea aquel normalmente vinculado a una dimensión mítica, no es menos cierto que el Perú “oficial” tiene también una dimensión mítica en la línea de lo tratado por Benjamin. Como señala Ubilluz, en relación con el fantasma de la nación cercada, en el caso de Rosa Cuchillo, "el mismo fantasma sostiene (...) el pachacuti, el eterno retorno de lo mismo, de la misma esencia andina premoderna, prehispánica incluso" (2009: 60). En el caso de La hora azul, se acepta "con la pasión resignada de la costumbre” que existe en el país una división infranqueable entre ricos y pobres, es decir, se plantea, como mencionamos, una ética tutelar que mantiene el status quo o, en palabras de Ublluz, "La nación cercada es así, en la novela, el soporte de la posición ético-política del buen Amo oligarca [los ricos]" (2009: 59). De este modo, el fantasma de la nación cercada constituye una polarización de dos discursos míticos en el Perú, la cual no es trascendida en las novelas que tratamos, sino que, por el contrario, ambas se mantienen en propuestas de lo ya conocido. 


\section{Conclusiones}

En este artículo, hemos sustentado que Rosa Cuchillo y Adrián Ormache atraviesan una experiencia de duelo, la cual tiene lugar a través de un proceso de búsqueda que se desencadena como una reacción por parte de los personajes ante una pérdida y que consume todas las energías del yo. Rosa Cuchillo emprende la búsqueda de Liborio, su hijo subversivo, mientras que Adrián Ormache rastrea el pasado de su padre a través de Miriam. En ambos casos, debido a que existe un distanciamiento con respecto al objeto perdido, nos encontramos ante procesos de duelo.

Sobre la base de estas historias particulares, analizamos los alcances sociales asociados a ellas. Ambas novelas reflejan a un Perú que es caracterizado a partir de dos discursos míticos que se ajustan ampliamente al fantasma de la nación cercada, porque, en Rosa Cucbillo, se hace presente el mito del eterno retorno andino que se caracteriza por el advenimiento de un pachacuti de runas encabezado por el héroe mesiánico Liborio, mientras que, en La hora azul, se muestra a un Adrián Ormache situado en el ámbito del mito del progreso: busca la comodidad futura y no está dispuesto a cambiar este objetivo.

En definitiva, estas novelas no proponen alternativas innovadoras con respecto a cómo enfrentarse con las consecuencias de la violencia política vivida en el Perú. En último término, el duelo de los protagonistas de las novelas se revelaría como un proceso conservador que se limita a proyectar, en el orden social mítico, el fantasma de la nación cercada, es decir, la repetición de propuestas de pseudosoluciones que no permiten superar la realidad de sociedad fragmentada que caracteriza al Perú. 


\section{Referencias bibliográficas}

BENJAMIN, Walter

2013 "Sobre el concepto de historia en Walter Benjamin”. Trad., Bolívar Echeverría. Chillán: Centro de Estudios Miguel Enríquez, 2013. Consulta: 10 de diciembre de 2013. <www. archivochile.com>.

Colchado Lucio, Óscar

2009 Rosa Cuchillo. Lima: Alfaguara.

Cornelio, José E.

2009 "Una ideología de la ficción: los 'Andes imaginarios' de Madeinusa y las aproximaciones de la crítica”. XXXVIII Congreso Internacional del Instituto Internacional de Literatura Iberoamericana: "Independencias: Memoria y Futuro". Washington, DC: Georgetown University. Consulta: 25 de noviembre de 2013. <www.iiligeorgetown2010.com>.

Cueto, Alonso

2007 La hora azul. Lima: Anagrama y Peisa.

DeBOrD, Guy

1995 La sociedad del espectáculo. Trad., Rodrigo Vicuña Narravo. Santiago: Ediciones Naufragio

FREUD, Sigmund

1986 “Duelo y melancolía”. En Obras completas. Vol. 14. 2ª ed. Ed., James Strachey. Trad., José Luis Etcheverry. Buenos Aires: Amorrortu Editores, 234-255. Impreso.

Galdo, Juan Carlos

2000 "Algunos aspectos de la narrativa regional contemporánea: los casos de Enrique Rosas Paravicino y Óscar Colchado Lucio”. Lexis 24, 1, 93-108.

Maceda Sotomayor, Diana Teresa

2011 Las mujeres en el Manuscrito de Huarochirí la sexualidad como ordenadora del cosmos. Tesis para optar el título de Licenciada en Lingüística y Literatura con mención en literatura hispánica. Lima: Pontificia Universidad Católica del Perú. 
PARedes, Martín

2009 "Una violencia de novale. Una entrevista a Víctor Vich por Martín Paredes”. Quebacer 174, 112-117.

Quiroz Ciriaco, Víctor Felipe Segundo

2006 Pensamiento andino y crítica postcolonial. Un estudio de Rosa Cuchillo de Óscar Colchado. Tesis para obtener el título professional de Licenciado en Literatura. Lima: Universidad Nacional Mayor de San Marcos.

Ritos y TRADICIONES DE HuAROCHIRÍ

2008 Ed. y trad., Gerald Taylor. Lima: Instituto Francés de Estudios Andinos, Instituto de Estudios Peruanos y Universidad Nacional Mayor de San Marcos. Impreso.

Ubilluz, Juan Carlos

2009 "El fantasma de la nación cercada”. Contra el sueño de los justos: la literatura peruana ante la violencia política. En Juan Carlos Ubilluz, Alexandra Hibbett y Víctor Vich. Lima: Instituto de Estudios Peruanos, 19-85.

VARgas Llosa, Mario

2009 La utopía arcaica. Lima: Alfaguara.

Vargas Llosa, Mario, Abraham Guzmán y Mario Castro

1983 "Informe de la comisión investigadora de los sucesos de Uchuraccay". Contra viento y marea. Vol. III, 79-114.

VicH, Víctor

2009 "Violencia, culpa y repetición: La bora azul de Alonso Cueto”. En Juan Carlos Ubilluz, Alexandra Hibbett y Víctor Vich 2009. Lima: Instituto de Estudios Peruanos, 233-246.

2010

"El discurso sobre la Sierra del Perú: la fantasía del atraso". Critica y emancipación. Revista latinoamericana de ciencias sociales. 2, 3, 253-266.

WinTTERBERG, Stella

2005 “El ángel de la historia en la pintura contemporánea”. En La mirada del ángel: en torno a las "Tesis sobre la bistoria" de Walter Benjamin. Ed., Bolívar Echeverría. México, DF: Universidad Autónoma de México, 195-208.

Fecha de recepción: 10/02/2016

Fecha de aceptación: 12/12/2016 